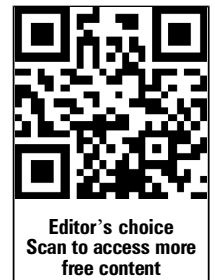

free content

- Additional material is published online only. To view please visit the journal online (http://dx.doi.org/10.1136/jech2013-202844).

${ }^{1}$ Institute of Medical Epidemiology, Biostatistics, and Informatics, Faculty of Medicine, University of Halle-Wittenberg, Halle (Saale), Germany

${ }^{2}$ German Diabetes Center, Leibniz Institute for Diabetes Research at Heinrich Heine University Düsseldorf, Institute for Biometry and Epidemiology, Düsseldorf, Germany

${ }^{3}$ Centre for Health and Society, Faculty of Medicine, Heinrich Heine University, Düsseldorf, Germany

\section{Correspondence to} Daniel Medenwald, Institute of Medical Epidemiology, Biostatistics, and Informatics, Medical Faculty, Martin-LutherUniversity of Halle-Wittenberg, Magdeburger Str. 8, Halle (Saale) 06112, Germany; daniel.medenwald@uk-halle.de

Received 14 May 2013 Revised 7 January 2014 Accepted 11 April 2014 Published Online First 8 May 2014

\section{(D) CrossMark}

To cite: Medenwald D, Kuss O. J Epidemiol Community Health 2014;68:869-873.

\title{
Mortality on match days of the German national soccer team: a time series analysis from 1995 to 2009
}

\author{
D Medenwald, ${ }^{1} 0 \mathrm{Kuss}^{2,3}$
}

\begin{abstract}
Background There is inconsistent evidence on population mortality, especially cardiovascular disease mortality, on match days of national soccer teams during particular international tournaments. This study examines the number of deaths in Germany on match days of the national soccer team during a long-term period including several tournaments.
\end{abstract}

Methods We analysed all registered daily deaths in Germany from 1995 to 2009 (11 225966 cases) using time series analysis methods. Following the Box/Jenkins approach, we applied a seasonal autoregressive integrated moving average model. To assess the effect of match days, we performed an intervention analysis by including a transfer function model representing match days of the national team in the statistical analyses. We conducted separate analyses for all matches and for matches during international tournaments (European and World Championships) only. Time series and results were stratified in terms of sex, age ( $<50$ years, $50-70$ years, $>70$ years) and cause of death (cardiovascular deaths, injuries, others). We performed a further independent analysis focusing only on the effect of match results (victory, loss, draw) and kind of tournament (international championships, qualifications, friendly matches).

Results Most of the results did not indicate a distinct effect of matches of the national team on general mortality. Moreover, all null value deviations were small when compared with the average number of daily deaths $(n=2270)$.

Conclusions There is no relevant increase or decrease in mortality on match days of the German national soccer team.

\section{INTRODUCTION}

The link between emotional stress and an enhanced risk of cardiovascular death is well established. ${ }^{1}{ }^{2}$ In particular, sports events such as soccer matches are capable of provoking strong emotions, which might cause a failure of the cardiovascular system, and thus a peak of death numbers in the population. The phenomenon of increased hospitalisation rates and emergency cases in the context of the Soccer World Cup 2006 in Germany was revealed by Wilbert-Lampen et al. ${ }^{3}$ The overall incidence of emergency cases on days when the German national team played was $2.66(95 \%$ CI 2.33 to $3.04)$-fold higher than in a control period immediately before the tournament. For men, the increase in incidence was 3.26 (95\% CI 2.78 to 3.84 )-fold the incidence during the control period, while the corresponding value was only 1.82 (95\% CI 1.44 to 2.31) in women. The authors attributed these findings to a substantial manifestation of emotional stress in the course of soccer matches. However, they did not deduce a general association between increased rate of mortality and soccer matches, but affiliated the findings to the importance of the World Championships. Apart from the study previously mentioned, other studies also reported an increase in cardiovascular events during soccer tournaments: Katz et $a l^{4}$ analysed data from Switzerland and found an increase in the number of sudden cardiac deaths during the World Cup 2002. They calculated an increase of $77 \%$ (95\% CI $63 \%$ to $94 \%$ ) for men and $33 \%$ (95\% CI $13 \%$ to $84 \%$ ) for women, respectively. Another study by Carroll et $a l^{5}$ focused on hospital admission due to myocardial infarction during the same tournament (World Cup 2002) in England and calculated a $25 \%$ (95 CI $8 \%$ to $44 \%$ ) increase within 2 days after the English team lost in a penalty shoot-out. Comparing deaths from acute myocardial infarction (AMI) and stroke on the day when the Dutch team was eliminated from the European Championship 1996 with a time span of 5 days before and after this day, respectively, Witte et $a l^{6}$ found a relative risk above 1 (1.51, 95\% CI 1.08 to 2.09) for men and a lower relative risk $(1.11,95 \%$ CI 0.8 to 1.56) in women to have died on this match day.

Only a few studies have examined deaths from cardiovascular events on match days within a time frame of several years, rather than during a single tournament. Kirkup and Merrick ${ }^{7}$ analysed 1094 soccer matches played by local teams in England. They estimated a relative risk of 1.28 (95\% CI 1.11 to 1.47) for deaths from AMI and stroke when the local teams lost at home compared with other match results.

In contrast to these results, there was no increase in mortality from AMI during the World Cup 2006 in a sample of 6699 deaths from a Bavarian public mortality registry. ${ }^{8}$ The authors attributed the findings to errors regarding the ascertainment of data. Analysing the daily mortality during the Soccer World Cup in France in 1998, Berthier and Boulay ${ }^{9}$ even found a decrease in deaths from myocardial infarction when the French team won the tournament. The authors reported a drop from an average number of 32.6 to 23.0 (relative risk: 0.71 , $95 \%$ CI 0.55 to 0.98 ) in men, which was similar in women but started 1 day before the final match. Along the same lines, Barone-Adesi $e a \mathrm{l}^{10}$ failed to find an increase in hospital admission in Italy during three international soccer competitions between 2002 and 2006. Examining cardiovascular 
deaths in France during the 1996 European Soccer Championship, Toubiana et $a l^{11}$ found a slight decrease in cardiac disease mortality on the last match day of the French national team; the relative risk was estimated to be $0.94(95 \%$ CI: 0.88 to 1.00 ) for men and 0.94 (95\% CI: 0.82 to 1.08 ) for women.

As this short review reveals, results are inconsistent and seem to depend on the analysed tournament, the year of the tournament and the considered area. Thus it is straightforward to ask whether possible effects are sustained when a larger amount of data encompassing several events is analysed. Even further, it is conceivable that less important matches such as qualifications and matches out of international tournaments have a lower impact. Moreover, detailed examinations of results and types of matches, such as qualifications and championships, have rarely been conducted. The purpose of this study is to fulfil this gap. We hypothesise that:

1. The numbers of deaths deviate from the expected numbers on days when the national team plays, as compared with days without any national team matches.

2. The increase/decrease in deaths in men surmounts the same effect in women.

3. Taking previous findings ${ }^{3}$ into account, we expect the strongest change in the number of deaths to occur in people aged less than 70 years.

4. Possible changes in death numbers are mainly due to changes in death due to cardiovascular reasons.

5. The meaning of a particular match as measured by the score and the respective type of competition affects the overall mortality on the match day.

\section{METHODS}

\section{Data acquisition}

The data were obtained from the microdata set of official statistics as provided for scientific use by the 'Research Data Centres (RDCs) of the Federal Statistical Office and the Statistical Offices of the Länder'. ${ }^{12}$ This anonymised data set includes all deaths registered in Germany from 1995 to 2009, that is, a time span of 15 years, and 11225966 cases in total. Each observation has information on the cause of death encoded by the International Classification of Diseases (ICD), date of death, date of birth, sex and place of birth. The cause of death is defined as the underlying disease that began a causal chain leading to death.

Data access and analysis took place via 'remote execution' where the user compiles an evaluation programme using dummy files, which is transmitted to the RDC. The programme itself is subsequently executed by the RDC and the results of the analysis are sent back to the user.

\section{Formation of disease entities and age groups}

Disease entities were defined by the 'ICD' V.9 until 1997 and V.10 after 1997.

We formed separate groups of cases depending on the cause of death (ICD-10/ICD-9 codes):

- external causes and injuries (S00-T98, V01-Y98/800-999), and more specifically death from car accidents (V01-V99/E 810-E829), and suicides (X60-84, X87; E950-E959);

- causes considering the circulatory system (I00-I99/390-429) with subgroups of myocardial infarction (I20-I25, 410+414) and stroke (I60-I69, 430-438);

- remaining causes, not specified in detail, taking the subgroup of deaths from chronic asthma and chronic obstructive pulmonary disease (J40-J47, 490-496) into account.
This grouping of entities was defined to compare causes from the circulatory system to those from external causes/injuries. Finally, decedents were classified by age into younger than 50 years, between 50 years and 70 years, and older than 70 years.

\section{Match importance and scores}

In a separate analysis we focused on matches by their importance, which was classified as follows: (1) matches in the context of international championships, that is, European and World Championships, (2) qualifications to European and World Championships, and (3) remaining and friendly matches. Possible scores were victories, losses and draws. The match days and the corresponding results are published by the German Football Association (Deutscher Fussball Bund). ${ }^{13}$ There were 23 victories, 8 losses and 6 draws in international competitions, and considerably more victories (44) and draws (17), but only 4 losses in the context of qualification matches, while the results of the remaining friendly matches encompassed 60 victories, 24 losses and 21 draws. This gives a total number of 207 single matches which were included in the analysis. As an overview, figure 1 displays the time course of all deaths and the time points of all considered matches.

\section{Statistical analysis}

Time series analysis and more specifically, seasonal autoregressive integrated moving average (SARIMA) models were used for statistical analysis. We estimated models (1) for the complete data set, (2) for men and women separately, and (3) in the subgroups of age and cause of death, separately for men and women. In a secondary analysis, we aimed to examine the impact of the importance of matches only. Therefore, we used the model for the time series of all deaths to detect an excess number of deaths with respect to match type and score.

Model identification was based on the algorithm introduced by Box and Jenkins. ${ }^{14} 15$ Details of model identification and parameter estimation are given in the online supplementary appendix. Results from the different SARIMA models are given as the excess number of deaths on match days, together with their corresponding 99\% CIs. We chose to give 99\% (instead of 95\%) CIs to account for the large number of reported CIs, thus minimising the risk of false positive findings due to multiple comparisons. All statistical analyses and data management were performed using SAS, V.9.2 (SAS, Cary, North Carolina, USA).

\section{RESULTS}

Considering all cases and relating them to the average number of daily deaths, there was virtually no excess of deaths on match days, for neither all matches nor international matches (table 1). In detail, we found 1.9 (99\% CI -13.5 to 17.3) fewer deaths than expected for all matches, and 0.1 (99\% CI -4.2 to 4.4 ) more deaths for international matches. Absence of a relevant effect is especially obvious when these numbers are compared with the average number of 2270 daily deaths in Germany during the observation period. Similar evidence of null effects and large CIs was observed when men and women were analysed separately. If any, there was a slight tendency for a lower number of deaths on match days than was expected from the time course, where the decrease in men $(-21.7 ; 99 \%$ CI -42.4 to -1.1$)$ for international matches exceeded the effect found in women $(-11.6 ; 99 \%$ CI -33.7 to 10.5$)$. Taking age and cause of death into account, excess deaths scattered randomly around the null value, again with a small reduction in the number of deaths on days of international 


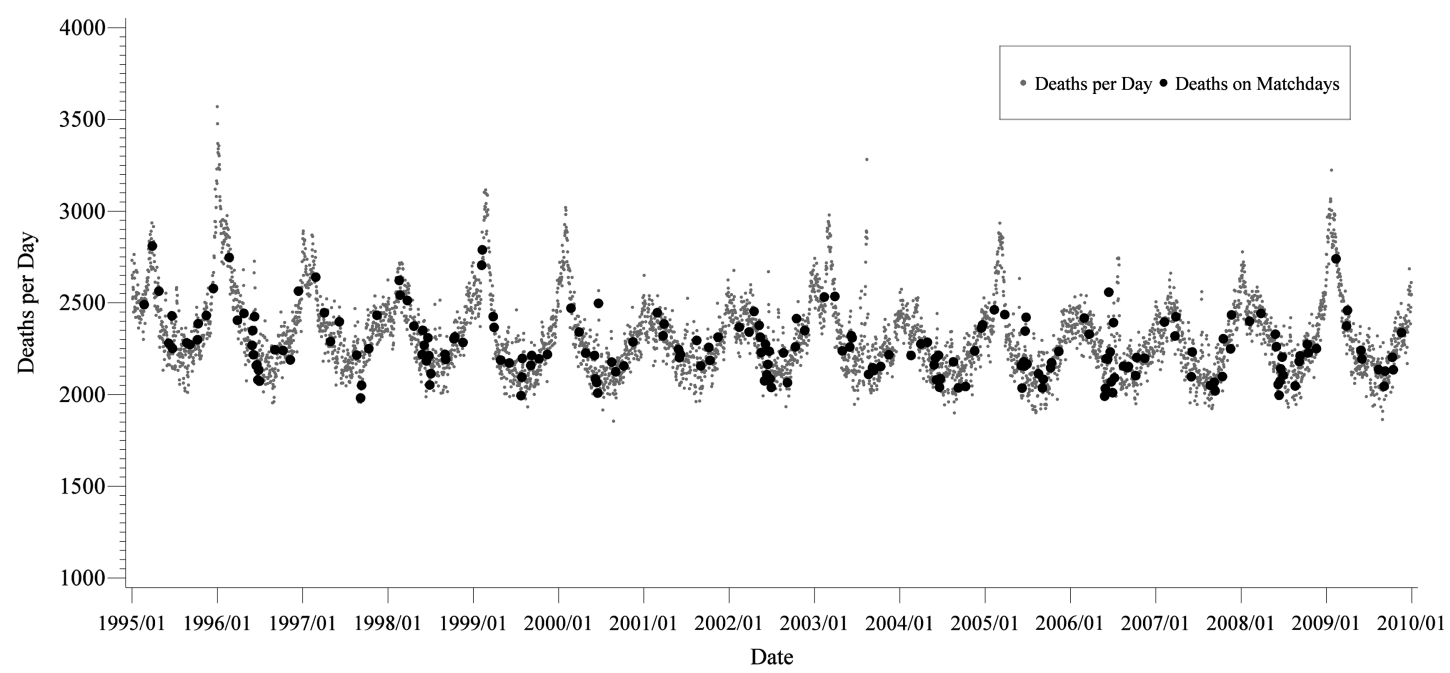

Figure 1 Time course of overall deaths and dates of considered match days. Numbers of deaths are displayed by grey dots; deaths on a match day of the German national team are indicated by black dots.

matches. Additionally, there was no relevant change in mortality when refined causes of death (see subgroups in table 1) were considered, while again wide CIs reflect a noticeable amount of statistical uncertainty.

As shown in table 2, the result of the respective match had nearly no effect on death numbers. A slight reduction in deaths was seen for international matches and a slight increase was observed for qualification matches. The greatest drop occurred when the national team won during international competitions, which was estimated to be 45.4 deaths (95\% CI 1.3 to 89.5 ). Despite this finding, estimates again showed considerable statistical uncertainty as indicated by their wide CIs.

In terms of the orders of the underlying SARIMA models, all analyses required the inclusion of a seasonal term with a period

Table 1 Frequencies, means and numbers of excess deaths differentiated by sex, age and cause of death, and applied model

\begin{tabular}{|c|c|c|c|c|c|}
\hline & Number of deaths & $\begin{array}{l}\text { Average number } \\
\text { of daily deaths }\end{array}$ & $\begin{array}{l}\text { All matches } \\
\text { Number of excess } \\
\text { deaths }(99 \% \mathrm{Cl})\end{array}$ & $\begin{array}{l}\text { International competition } \\
\text { Number of excess } \\
\text { deaths }(99 \% \mathrm{Cl})\end{array}$ & Final model \\
\hline All cases & 11225966 & 2270.2 & $-1.9(-17.3$ to 13.5$)$ & $0.1(-4.2$ to 4.4$)$ & $\operatorname{ARIMA}(2,0,2)(0,1,1)_{7}$ \\
\hline Men & 5238004 & 1063.8 & $2.3(-6.8$ to 11.4$)$ & $-21.7(-42.4$ to -1.1$)$ & $\operatorname{ARIMA}(2,0,2)(0,1,1)_{7}$ \\
\hline$<50$ years & 458340 & 93.4 & $0.1(-2.1$ to 2.2$)$ & $-2.0(-7.0$ to 2.9$)$ & $\operatorname{ARIMA}(1,0,1)(0,1,1)_{7}$ \\
\hline $50-70$ years & 1628679 & 332.2 & $1.3(-3.0$ to 5.7$)$ & $-3.6(-13.6$ to 6.5$)$ & $\operatorname{ARIMA}(2,0,2)(0,1,1)_{7}$ \\
\hline$>70$ years & 3150985 & 643.2 & $0.8(-5.5$ to 7.1$)$ & $-15.6(-30.0$ to -1.2$)$ & $\operatorname{ARIMA}(2,0,2)(0,1,1)_{7}$ \\
\hline External causes/injuries & 288625 & 58.9 & $-0.3(-2.1$ to 1.4$)$ & $-1.2(-5.2$ to 2.8$)$ & $\operatorname{ARIMA}(1,0,2)(0,1,1)_{7}$ \\
\hline Car accidents & 74970 & 13.8 & $0.5(-0.3$ to 1.3$)$ & $0.5(-1.4$ to 2.3$)$ & $\operatorname{ARIMA}(2,0,1)(0,1,1)$ \\
\hline Suicides & 120120 & 21.9 & $-0.4(-1.3$ to 0.6$)$ & $-0.2(-2.4$ to 2$)$ & $\operatorname{ARIMA}(1,0,1)(0,1,1)$ \\
\hline Circulatory system & 2004967 & 409.2 & $-0.5(-5.4$ to 4.4$)$ & $-7.3(-18.6$ to 4.1$)$ & $\operatorname{ARIMA}(2,0,1)(0,1,1)_{7}$ \\
\hline Myocardial infarction & 1156005 & 210.9 & $1.3(-1.8$ to 4.4$)$ & $0.1(-7.4$ to 7.7$)$ & $\operatorname{ARIMA}(2,0,1)(0,1,1)$ \\
\hline Stroke & 428211 & 78.2 & $-0.9(-2.7$ to 0.9$)$ & $-2.2(-6.6$ to 2.1$)$ & $\operatorname{ARIMA}(1,0,1)(0,1,1)$ \\
\hline Remaining causes & 2944412 & 599.8 & $2.7(-3.4$ to 8.8$)$ & $-12.6(-26.6$ to 1.3$)$ & $\operatorname{ARIMA}(1,0,3)(0,1,1)_{7}$ \\
\hline Obstructive airway disease & 234301 & 42.8 & $0.6(-0.7$ to 1.9$)$ & $-0.7(-3.8$ to 2.4$)$ & $\operatorname{ARIMA}(2,0,2)(0,1,1)$ \\
\hline Women & 5987962 & 1218.6 & $-4.0(-13.7$ to 5.7$)$ & $-11.6(-33.7$ to 10.5$)$ & $\operatorname{ARIMA}(2,0,1)(0,1,1)_{7}$ \\
\hline$<50$ years & 227861 & 46.6 & $-0.7(-2.1$ to 0.8$)$ & $-0.7(-3.9$ to 2.5$)$ & $\operatorname{ARIMA}(2,0,1)(0,1,1)_{7}$ \\
\hline $50-70$ years & 833416 & 170.1 & $-2.0(-4.8$ to 0.9$)$ & $-3.8(-0.4$ to 2.8$)$ & $\operatorname{ARIMA}(2,0,1)(0,1,1)_{7}$ \\
\hline$>70$ years & 4926685 & 1004.4 & $-1.0(-9.5$ to 7.5$)$ & $-7.0(-26.4$ to 12.5$)$ & $\operatorname{ARIMA}(2,0,1)(0,1,1)_{7}$ \\
\hline External causes/injuries & 171766 & 35.1 & $0.5(-0.7$ to 1.8$)$ & $-0.4(-3.3$ to 2.5$)$ & $\operatorname{ARIMA}(1,0,1)(0,1,1)_{7}$ \\
\hline Car accidents & 24409 & 6.4 & $0.3(-0.3$ to 0.9$)$ & $-0.3(-1.8$ to 1.1$)$ & $\operatorname{ARIMA}(1,0,1)(0,1,1)$ \\
\hline Suicides & 43045 & 8.4 & $0.3(-0.3$ to 0.8$)$ & $-0.1(-1.3$ to 1.2$)$ & $\operatorname{ARIMA}(1,0,1)(0,1,1)$ \\
\hline Circulatory system & 2803928 & 572.1 & $0.5(-5.4$ to 6.4$)$ & $-2.4(-15.9$ to 11.3$)$ & $\operatorname{ARIMA}(1,0,2)(0,1,1)_{7}$ \\
\hline Myocardial infarction & 1258717 & 229.7 & $0.7(-2.6$ to 3.9$)$ & $-4.9(-12.8$ to 2.9$)$ & $\operatorname{ARIMA}(1,0,1)(0,1,1)$ \\
\hline Stroke & 742532 & 135.5 & $0.6(-1.8$ to 3$)$ & $2.2(-3.5$ to 7.9$)$ & $\operatorname{ARIMA}(3,0,1)(0,1,1)$ \\
\hline Remaining causes & 3012268 & 614.5 & $-4.3(-10.6$ to 2.0$)$ & $-9.0(-23.5$ to 5.5$)$ & $\operatorname{ARIMA}(1,0,2)(0,1,1)_{7}$ \\
\hline Obstructive airway disease & 163198 & 29.8 & $-0.3(-1.4$ to 0.8$)$ & $0.5(-2.1$ to 3.1$)$ & $\operatorname{ARIMA}(2,0,2)(0,1,1)$ \\
\hline
\end{tabular}

Causes of death (External causes/injuries, Circulatory system, Obstructive airway disease) as defined by 'Research Data Centres (RDCs) of the Federal Statistical Office and the Statistical Offices of the Länder'12 with respective subgroups. 
Table 2 Number of excess deaths by match importance and score*

\begin{tabular}{llcc}
\hline Type of match & Score & $\begin{array}{l}\text { Number of } \\
\text { matches }\end{array}$ & $\begin{array}{l}\text { Number of excess } \\
\text { deaths }(99 \% \text { Cl) }\end{array}$ \\
\hline All events & Victories & 127 & $-3.3(-22.5$ to 15.9$)$ \\
& Losses & 36 & $5.5(-32.0$ to 42.9$)$ \\
International championships & Draws & 44 & $-3.4(-37.1$ to 30.3$)$ \\
& All & 37 & $-33.7(-68.8$ to 1.4$)$ \\
& Victories & 23 & $-45.4(-89.5$ to -1.3$)$ \\
Qualifications & Losses & 8 & $-16.0(-93.7$ to 61.8$)$ \\
& Draws & 6 & $-9.7(-93.6$ to 74.2$)$ \\
& All & 65 & $16.5(-9.4$ to 42.5$)$ \\
Rest/friendly matches & Victories & 44 & $15.7(-15.7$ to 47.0$)$ \\
& Losses & 4 & $71.0(-31.5$ to 173.5$)$ \\
& Draws & 17 & $4.7(-46.5$ to 56.0$)$ \\
& All & 105 & $-2.6(-25.2$ to 20.1$)$ \\
& Victories & 60 & $-1.2(-30.3$ to 27.9) \\
& Losses & 24 & $-0.5(-47.5$ to 46.6$)$ \\
& Draws & 21 & $-9.5(-62.4$ to 43.5$)$
\end{tabular}

${ }^{*}$ As estimated by the respective pulse functions from the $\operatorname{ARIMA}(2,0,2)(0,1,1)_{7}$ model on all 11225966 deaths.

of 7 days, indicating a weekly cycle of deaths. Model orders for the actual non-seasonal ARIMA parts were similar across all models with an order for the autoregressive and moving average parts of one or two in nearly all cases.

\section{DISCUSSION}

As our findings indicate, there is no relevant increase in deaths on match days of the German national soccer team. On the contrary, a decrease occurred in the majority of estimated pulse effects, which was strongest in the case of victories in international competitions. As these matches are characterised by high importance and significance, a cheerful mood might contribute to these effects. A relevant increase in deaths only occurred when the team lost in qualification matches, but the low number of matches and the wide CIs point to a random chance. We could not find an effect of losses quantitatively similar to that of Toubiana et al. ${ }^{11}$ Thus, it can be concluded that matches of the national team do not affect people's overall health adversely.

Our results are in contrast to the mentioned findings of Wilbert-Lampen et al. ${ }^{3}$ However, as the authors of this study focused on emergencies in the major city of Munich, their findings are not fully comparable with our study. Soccer matches in larger cities have the characteristics of mass gatherings such as concerts or outdoor festivals. It is easily comprehensible that medical emergencies increase when huge numbers of people gather in a small area. ${ }^{16}$ Such an increase cannot be generalised to the general population, which is not exposed to the risk of such mass events. Furthermore, it is also feasible that the number of emergencies rises while mortality decreases. The potentially biasing effect arising from the analysis of only one major city might also influence the findings of Wilbert-Lampen et al. ${ }^{3}$ Moreover, a strength of our study is that it assesses the effects of several international championships. As such, peaks and drops seen with single events as in Wilbert-Lampen $e t a l^{3}$ or further previous studies, ${ }^{5}{ }^{6}$ might average out across several competitions. Finally, other studies have reported a decrease in deaths ${ }^{9} 11$ or no effect of match days of national teams on mortality, ${ }^{10}$ concurring with our findings.

\section{Limitations}

We used a retrospective approach on aggregated data, and therefore it was not possible to consider information from individuals such as the importance that they attributed to a match or the setting where they experienced the match. Thus, it is feasible that some individuals were indeed negatively affected by spectating at soccer matches. However, the purpose of our study was to re-evaluate the previous findings of peaks of emergencies and number of deaths, respectively, on a larger epidemiological scale over several years. Additionally, we investigated not one single competition or match, but 207 matches in total, which means that a bias due to environmental factors would be unlikely. Nevertheless, we cannot fully exclude such distractions, especially in match constellations that are only rarely observed (eg, losses in qualifications). In general, matches are not equally represented in quantitative terms, which makes findings in groups including many matches more reliable.

The inaccuracy of death certificates, which has been reported previously ${ }^{17-19}$ might also provoke imprecisions of results regarding the distinguished groups of diseases.

Nevertheless, our study gives strong evidence that overall mortality in Germany is not affected by soccer matches of the national team.

\section{What is already known on this subject?}

- Results of previous studies were inconsistent and indicated an increase, but also a decrease in mortality/morbidity on match days of national soccer teams.

- Most studies examined only soccer matches during singular tournaments.

\section{What this study adds?}

- This study examined all deaths (more than 11 Mio cases) in Germany and took all soccer matches of the national soccer team from 1995 to 2009 into account.

- Using methods of time series analysis no convincing increase or decrease in mortality could be found on match days of the German national team.

- If any, a slight drop in overall mortality was observed when the national team won in international championships.

Acknowledgements The authors thank Mr Michael Rößner from the Research Data Centres in Halle (Saale) for his constructive and professional cooperation, the high quality of his work and the fast release of results.

Contributors DM had the initial idea, organised data access and communication with the statistical offices, performed the statistical analysis, and drafted the manuscript. He is the guarantor for the study. OK assisted with planning of the study, data analysis and data interpretation and revised the manuscript critically for important intellectual content.

\section{Competing interests None.}

Provenance and peer review Not commissioned; externally peer reviewed.

Data sharing statement Since the data are provided by the Federal Statistical Office, we cannot offer any additional unpublished data.

\section{REFERENCES}

1 Stewart I. Coronary disease and modern stress. Int J Epidemiol 2002;31:1103-7.

2 Russ TC, Stamatakis E, Hamer M, et al. Association between psychological distress and mortality: individual participant pooled analysis of 10 prospective cohort studies. BMJ 2012;345:e4933.

3 Wilbert-Lampen U, Leistner D, Greven $\mathrm{S}$, et al. Cardiovascular events during World Cup soccer. N Engl J Med 2008;358:475-83. 
4 Katz E, Metzger J, Marazzi A, et al. Increase of sudden cardiac deaths in Switzerland during the 2002 FIFA World Cup. Int I Cardiol 2006;107:132-3.

5 Carroll D, Ebrahim S, Tilling K, et al. Admissions for myocardial infarction and World Cup football: database survey. BMJ 2002;325:1439-42.

6 Witte DR, Bots ML, Hoes AW, et al. Cardiovascular mortality in Dutch men during 1996 European football championship: Iongitudinal population study. BMJ 2000;321:1552-4.

7 Kirkup W, Merrick DW. A matter of life and death: population mortality and football results. J Epidemiol Community Health 2003;57:429-32.

8 Wilbert-Lampen U, Nickel T, Scheipl F, et al. Mortality due to myocardial infarction in the Bavarian population during World Cup Soccer 2006. Clin Res Cardiol 2011:100:731-6.

9 Berthier F, Boulay F. Lower myocardial infarction mortality in French men the day France won the 1998 World Cup of football. Heart 2003:89:555-6.

10 Barone-Adesi F, Vizzini L, Merletti F, et al. It is just a game: lack of association between watching football matches and the risk of acute cardiovascular events. Int J Epidemiol 2010;39:1006-13.

11 Toubiana L, Hanslik T, Letrilliart L. French cardiovascular mortality did not increase during 1996 European football championship. BMJ 2001;322:1306.
12 Statistische Ämter des Bundes und der Länder. ["Research Data Centres of the Federal Statistical Office and the statistical offices of the Länder"] (Ed). A standard for the release of microdata. Arbeitspapier (working paper), 2006.

13 Deutscher Fussball Bund. Alle Spiele http://www.dfb.de/index.php?id=500001 (accessed 19 Apr 2013).

14 Box GEP JGM. Time series analysis: forecasting and control. San Francisco: Holden-Day [Holden-Day series in time series analysis and digital processing], 1976.

15 Helfenstein U. Box-Jenkins modelling in medical research. Stat Methods Med Res 1996;5:3-22.

16 Soomaroo L, Murray V. Disasters at mass gatherings: lessons from history. PLoS Curr 2012;4:RRN1301.

17 Percy C, Stanek E, Gloeckler L. Accuracy of cancer death certificates and its effect on cancer mortality statistics. Am J Public Health 1981;71:242-50.

18 Hunt LW, Silverstein MD, Reed CE, et al. Accuracy of the death certificate in a population-based study of asthmatic patients. JAMA 1993;269:1947-52.

19 Modelmog D, Rahlenbeck S, Trichopoulos D. Accuracy of death certificates: a population-based, complete-coverage, one-year autopsy study in East Germany. Cancer Causes Control 1992;3:541-6. 